\title{
On the relationship between strabismic amblyopia and eccentric fixation
}

\author{
R. F. HESS \\ From the Department of Optometry, University of Melbourne, Victoria, Australia
}

SUMMARY Landolt $\mathrm{C}$ and grating acuity are compared with that normally expected of the eccentric fixation region for 10 strabismic amblyopes. The findings suggest that 2 populations of amblyopes exist. For some amblyopes visual function is that predicted of the eccentric region used for fixation, whereas for other amblyopes there is a further pathological reduction in visual function. These findings may have an important bearing on the type of orthoptic treatment used for amblyopia.

The relationship between the magnitude of the visual abnormality and the degree of eccentric fixation in strabismic amblyopia has been a controversial issue for many years. Although much research has been directed towards understanding this issue, only 2 studies have tackled the problem quantitatively, and they have produced results which seem to be contradictory.

Flom and Weymouth (1961) found a linear relationship between the minimum angle of resolution and the degree of eccentric fixation for 9 amblyopic subjects. Furthermore, the slope of this function (1.79 $\mathrm{min}$ of arc/deg of eccentric fixation) corresponded reasonably well with that obtained for normal untrained subjects $(1.77 \mathrm{~min}$ arc/deg of eccentric fixation) for eccentric viewing. This result led to the conclusion that the decline in acuity for amblyopic eyes could be ascribed to the expected normally low acuity of the eccentric region used for fixation. Contrary to this view, Alpern et al. (1967) found that the function relating amblyopic letter acuity and eccentric fixation did not coincide with that describing the acuity loss of the normal peripheral retina. They concluded that in strabismic amblyopia a further pathological loss of acuity is superimposed upon the normally low acuity expected of the eccentric retinal area used for fixation.

This conflict which has developed concerning the relationship between the visual abnormality and the degree of eccentric fixation in amblyopia nceds to be reassessed, because it has an important bearing on the nature, cause, and treatment of amblyopia and the role of the eccentric fixation in this condition. The present investigation reassesses this problem by com-

Address for reprints: Dr R. F. Hess, Physiological Laboratory, Downing Street, Cambridge CB2 3EG paring letter and grating acuity for centrically and eccentrically fixating amblyopes with that expected of the normal peripheral retina. Grating acuity offers a number of important advantages over letter acuity for this type of investigation. It represents a cognitively, spatially, and orientationally simpler task then letter acuity, and its accuracy is equal for normal and amblyopic eyes (Hess and Howell, in press) and does not vary as a function of eccentric viewing.

\section{Apparatus and methods}

\section{ACUITY TESTS}

Landolt $C$ acuity.-A frequency-of-seeing curve was constructed from multiple (28) presentations of different sized single Landolt Cs (approximately $100 \%$ contrast), and the acuity was taken as the gap size at which $\mathbf{P}=0 \cdot 5$. This threshold was determined by probit analysis (Finney, 1947) of the frequencyof-seeing data. No temporal factor was incorporated in the test, although the subjects were asked to respond promptly after the Landolt $\mathrm{C}$ was presented. The background luminance was $30 \mathrm{~cd} / \mathrm{m}^{2}$, the subjects were optically corrected, and a $3 \mathrm{~mm}$ artificial pupil was used. The natural pupil was dilated and accommodation paralysed with 2 drops of $2 \%$ homatropine prior to the refraction.

Grating acuity.-Vertical, spatially modulated sine-wave gratings of variable contrast and frequency were generated on the screen of a modified BWD oscilloscope by the method and equipment previously described (Hess and Howell, in press). The space-averaged luminance was $30 \mathrm{~cd} / \mathrm{m}^{2}$ and the contrast modulation which occurred about this luminance was adjusted by the subject with an 80position switched logarithmic attenuator. The oscil- 
loscope screen was masked down to a $7.5 \mathrm{~cm}$ circular aperture. A $100 \times 75 \mathrm{~cm}$ white surround screen was obliquely illuminated to the same luminance (3\% difference at aperture edge) and

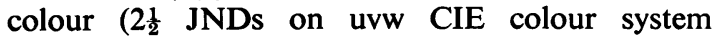
(Wyszecki, 1963). The room illumination was adjusted by means of indirect lighting to approximate to that of the screen and surround. The viewing distance from the oscilloscope was varied from $114 \mathrm{~cm}$ for spatial frequencies up to $10 \mathrm{c} / \mathrm{deg}$ to $342 \mathrm{~cm}$ for higher spatial frequencies. The field size therefore varied from $3 \cdot 7$ to $1 \cdot 2^{\circ}$. Subjects were located by means of a headrest and all observations were made with a 3-mm diameter artificial pupil, mydriasis, and cycloplegia. Care was taken in the centering of the artificial pupil so that maximum acuity was achieved (Campbell and Gregory, 1960). Two drops of $2 \%$ homatropine were instilled in each eye prior to the refraction. A careful clinical refraction was performed with the artificial pupils in place, and then the subject's prescription was modified for the testing distances used.

The method of adjustment was used in determining contrast thresholds. Instructions and training were standardised for all subjects to minimise threshold criterion changes and so to facilitate intersubject comparisons. The experimental protocol was such that contrast sensitivity for each spatial frequency was measured for the normal and amblyopic eye alternately. This design allows a more valid intrasubject comparison between normal and amblyopic curves. Five readings were taken at each spatial frequency tested.

Sine-wave grating acuity was estimated by extrapolation of the high frequency contrast sensitivity results. The high frequency sine-wave contrast sensitivity results were fitted by linear regression on semilog co-ordinates (Campbell et al., 1966) and then extrapolated to the abscissa. This technique was adopted because it was impossible to generate $100 \%$ contrast stimuli on a video display. The frequency response and contrast linearity of the video monitor were checked with a PIN photo diode.

\section{ECCENTRIC FIXATION MEASUREMENT}

A battery of tests were used to assess the fixation pattern of the amblyopic and normal eyes tested. These were: (1) Maxwell's spot; (2) Haidinger's brushes; (3) visuscopy; and (4) fixation photography. None of these tests are satisfactory alone for reasons which will be discussed; however, the combined result of all the tests gives a greater degree of confidence concerning the degree of eccentric fixation.

Maxwell's spot.-The subject viewed a retroilluminated bull's eye target which was located 282 cm away (rings ranged from $\frac{1}{2}^{\circ}$ diameter to $4^{\circ}$ diameter in $\frac{1}{2}^{\circ}$ steps) through alternating purple (Kodak Wrattan No 34) and neutral filters. The two filters were matched for transmittance with a Spectra Pritchard spot photometer for the viewing conditions of the test. The subject adjusted the speed of alternation (for any desired mark space ratio) and the target illumination for optimum viewing of the entoptic spot. The most common alternation frequency ( 0.5 mark space ratio) and target illumination was 0.5 to 1 alternation $/ \mathrm{s}$ and $4 \mathrm{~cd} / \mathrm{m}^{2}$ respectively. The subjects were first shown the spot with their good eye and asked to arrange optimum viewing conditions. They were asked to describe and sketch the shape and size of the spot and estimate its centre with respect to the fixation target. Three estimations were recorded, and the procedure was repeated for the amblyopic eye. Although there was considerable variation in the reported shape and size of the spot, the 30 min central dark disc was always seen (except for Case 7, who did not perceive the spot at all), and its centre was taken as an estimate of fixation.

Haidinger's brushes. The subject viewed a retroilluminated bull's eye target (similar to that already described for the Maxwell spot test) through a blue filter (Kodak Wrattan No. 50) and rotating Polaroid (HN-22) filter. The subject adjusted the speed of rotation of the Polaroid filter and the target luminance for optimum viewing of Haidinger's brushes. The most commonly selected speed of rotation and target luminance through the filters was 60-300 RPM and $60 \mathrm{~cd} / \mathrm{m}^{2}$ respectively. The same procedure was adopted as for the previous test; three determinations of the pivot point of the rotating brushes were first made for the normal and then for the amblyopic eye. The angular size of the brushes was typically $1^{\circ}$, and, although in some cases the central region was not seen, the point about which the outer structure appeared to rotate could be accurately estimated with respect to the fixation centre.

Visuscopy and fixation photography. The Keeler specialist visuscope/euthyscope set was used in this investigation. For fixation photography a Topcon retinal camera (model TRC-J) was especially modified for this task by the inclusion of a target (photographically reduced target on a $35 \mathrm{~mm}$ slide), which could be introduced into the illumination system, at the point conjugate with the retina for an emmetropic eye. At another location in the illumination system lenses could be inserted to focus correctly the fixation target for myopic, presbyopic, or highly hyperopic subjects. Twenty photographs were taken for each subject of the fixation relationship for the normal and amblyopic eye. The fundus slides were 
Table 1 Eccentric fixation measurements for the 10 strabismic amblyopes tested

\begin{tabular}{|c|c|c|c|c|c|}
\hline \multirow[b]{2}{*}{ Case } & \multicolumn{5}{|l|}{ Anblyopic eyes } \\
\hline & Maxwell's spot & Haidinger's brushes & Visuscope & Fixation photography & Mean (retina) \\
\hline 1 & $\begin{array}{l}\text { Right eye } \\
13 \cdot 2^{\prime} \pm 4 \cdot 3^{\prime} \\
\text { (Nasal) }\end{array}$ & $\begin{array}{l}28^{\prime} \pm 4^{\prime} \\
\text { (Nasal) }\end{array}$ & $\begin{array}{l}1^{\circ} \pm 30^{\prime} \\
\text { (Nasal) }\end{array}$ & $\begin{array}{l}1 \cdot 8^{\circ} \pm 30^{\prime} \\
(\mathrm{Nasal})\end{array}$ & $\begin{array}{l}52 \cdot 3^{\prime} \\
\text { (Nasal) }\end{array}$ \\
\hline 2 & $\begin{array}{l}\text { Right eye } \\
8 \cdot 5^{\prime} \pm 12^{\prime} \\
\text { (Temporal) }\end{array}$ & $\begin{array}{l}7 \cdot 9^{\prime} \pm 2^{\prime} \\
\text { (Temporal) }\end{array}$ & Central & Central & $\begin{array}{l}4 \cdot 1^{\prime} \\
\text { (Central temporal) }\end{array}$ \\
\hline 3 & $\begin{array}{l}\text { Left eye } \\
1 \cdot 7^{\circ} \pm 7^{\prime} \\
\text { (Temporal) }\end{array}$ & $\begin{array}{l}1 \cdot 4^{\circ} \pm 20^{\prime} \\
\text { (Temporal) }\end{array}$ & No reflex & $\begin{array}{l}2 \cdot 8^{\circ} \\
\text { (Temporal) }\end{array}$ & $\begin{array}{l}1.96^{\circ} \\
\text { (Temporal) }\end{array}$ \\
\hline 4 & $\begin{array}{l}\text { Left eye } \\
2 \cdot 6^{\circ} \pm 20^{\prime} \\
\text { (Inferior temporal) }\end{array}$ & $\begin{array}{l}2 \cdot 2^{\circ} \pm 10^{\prime} \\
\text { (Inferior temporal) }\end{array}$ & No reflex & $\begin{array}{l}3^{\circ} \\
\text { (Inferior temporal) }\end{array}$ & $\begin{array}{l}2 \cdot 6^{\circ} \\
\text { (Inferior temporal) }\end{array}$ \\
\hline 6 & $\begin{array}{l}\text { Left eye } \\
1 \cdot 8^{\circ} \pm 20^{\prime} \\
\text { (Nasal) }\end{array}$ & $\begin{array}{l}2^{\circ} \pm 20^{\prime} \\
\text { (Nasal) }\end{array}$ & $\begin{array}{l}1 \cdot 5^{\circ} \pm 30^{\prime} \\
\text { (Nasal) }\end{array}$ & $\begin{array}{l}1 \cdot 4^{\circ} \pm 30^{\prime} \\
\text { (Nasal) }\end{array}$ & $\begin{array}{l}1 \cdot 3^{\circ} \\
(\text { Nasal) }\end{array}$ \\
\hline 7 & $\begin{array}{l}\text { Left eye } \\
\text { Not seen }\end{array}$ & $\begin{array}{l}2 \cdot 1^{\circ} \pm 15^{\prime} \\
\text { (Temporal) }\end{array}$ & $\begin{array}{l}3^{\circ} \pm 30^{\prime} \\
\text { (Temporal) }\end{array}$ & $\begin{array}{l}2 \cdot 5^{\circ} \pm 30^{\prime} \\
\text { (Temporal) }\end{array}$ & $\begin{array}{l}2 \cdot 5^{\circ} \\
\text { (Temporal) }\end{array}$ \\
\hline 8 & $\begin{array}{l}\text { Right eye } \\
2 \cdot 0^{\circ}+18^{\prime} \\
(\text { Nasal })\end{array}$ & $\begin{array}{l}2 \cdot 1^{\circ} \pm 17^{\prime} \\
\text { (Nasal) }\end{array}$ & $\begin{array}{l}1 \cdot 5^{\circ}+30^{\prime} \\
(\mathrm{Nasal})\end{array}$ & $\begin{array}{l}1 \cdot 6^{\circ} \pm 30^{\prime} \\
\text { (Nasal) }\end{array}$ & $\begin{array}{l}1 \cdot 8^{\circ} \\
\text { (Nasal) }\end{array}$ \\
\hline 9 & $\begin{array}{l}\text { Right eye } \\
\text { Central }\end{array}$ & Central & Central & Central & Central \\
\hline
\end{tabular}

Normal eyes: Maxwell's spot: Normal variation 7'-14'. Haidinger's brushes: Normal variation 2.6-12'

projected and the target position (dimensions: outer ring $2^{\circ}$ in diameter, inner fixation spot 30 minutes diameter) was assessed relative to foveal landmarks. The distance from the fovea to the optic disc centre was measured and taken to be $17^{\circ}$ (Van Buren, 1963). The results of these 4 tests for eccentric fixation are summarised in Table 1.

\section{SUBJECTS}

With one exception (Case 4, high anisometropia) only subjects who satisfied the following requirements were selected. These requirements were: (1) no high unilateral or bilateral astigmatism; (2) no high anisometropia; (3) a normal fixing eye (i.e., visual acuity correctable to at least $6 / 6$ and no signs of ocular disease); (4) strabismus; (5) full orthoptic treatment and/or strabismic amblyopia history available from the departmental clinic; (6) reliable observer; and (7) no other ocular abnormality present. These requirements ensured that only strabismic amblyopia was studied and that there were no confounding influences from spherical ametropic amblyopias, meridional amblyopia, or other ocular abnormalities which may be associated with a strabismus. The clinical data for these strabismic amblyope representatives are summarised in Table 2.

\section{Results}

Table 1 shows the degree of eccentric fixation recorded from the 4 tests used, the average of which was taken as the best estimate and appears in Table 2. For 3 patients visuscopy was useless, as no foveolar reflex was present, and for 1 patient Maxwell's spot was not seen with her amblyopic eye. There may be grounds for thinking that visuscopy and fixation photography might produce greater degrees of eccentric fixation, perhaps as an artefact of their very high luminances, as it has been reported that the fixation eye movements in the amblyopic eye increase in amplitude in very bright light (Von Noorden and Burian, 1958; Lawwill, 1966). In only 5 of the patients was the degree of eccentric fixation greater for these high luminance tests and for 3 out of the 5 this difference was less than $\frac{1}{2}^{\circ}$, which is the 
Table 2 Conventional clinical data for the 10 strabismic subjects

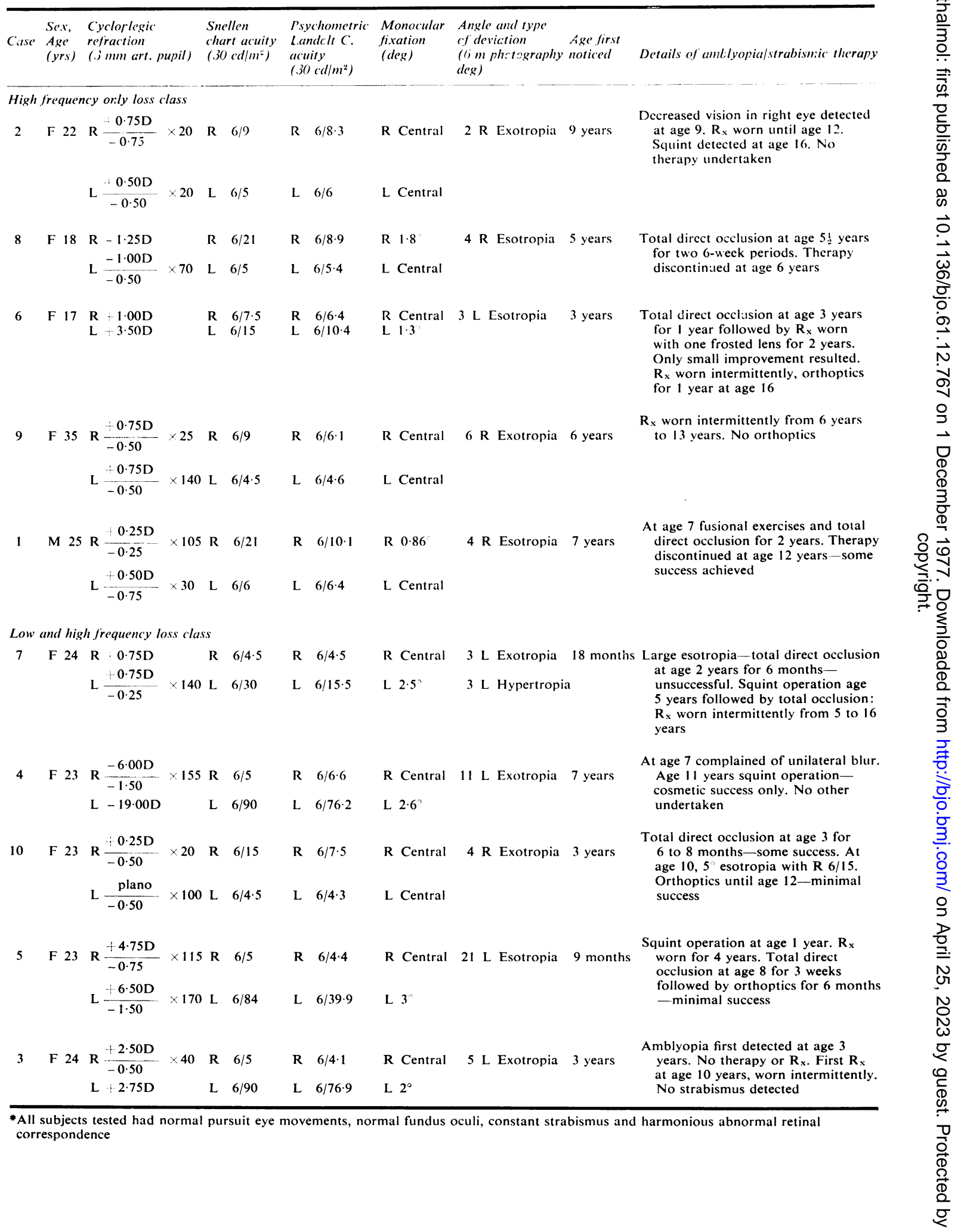




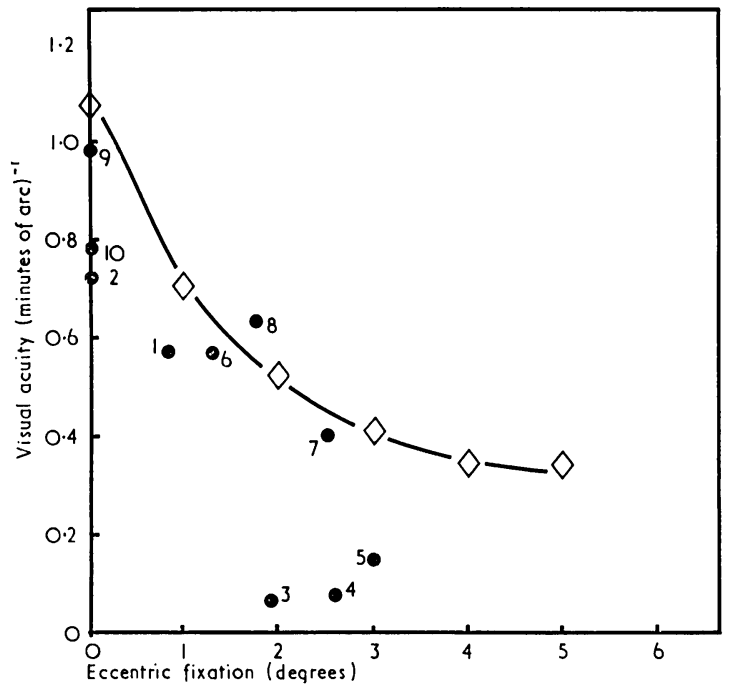

accuracy estimate of these tests. The range of variation for the normal eyes for Maxwell's spot and Haidinger's brushes was 7 to $14^{\prime}$ and 2.6 to $12^{\prime}$ respectively. The normal eyes' range of variation for visuscopy and fixation photography was within $20 \mathrm{~min}$ of the fovea. The degree of eccentric fixation in all except Case 7 was less than the angle of strabismus, an observation which agrees with previous investigations (Von Noorden, 1970a, b).

Fig. 1 shows a comparison between the results of Millodot (1966) for normal letter acuity (single Landolt $\mathrm{C}$ acuity for 3 subjects using an identical

Fig. 1 The relationship between single Landolt $C$ psychometric acuity for centrically and eccentrically fixating amblyopes (filled symbols) and the normal Landolt $C$ acuity of the peripheral retina (open symbols). Case numbers shown against dots
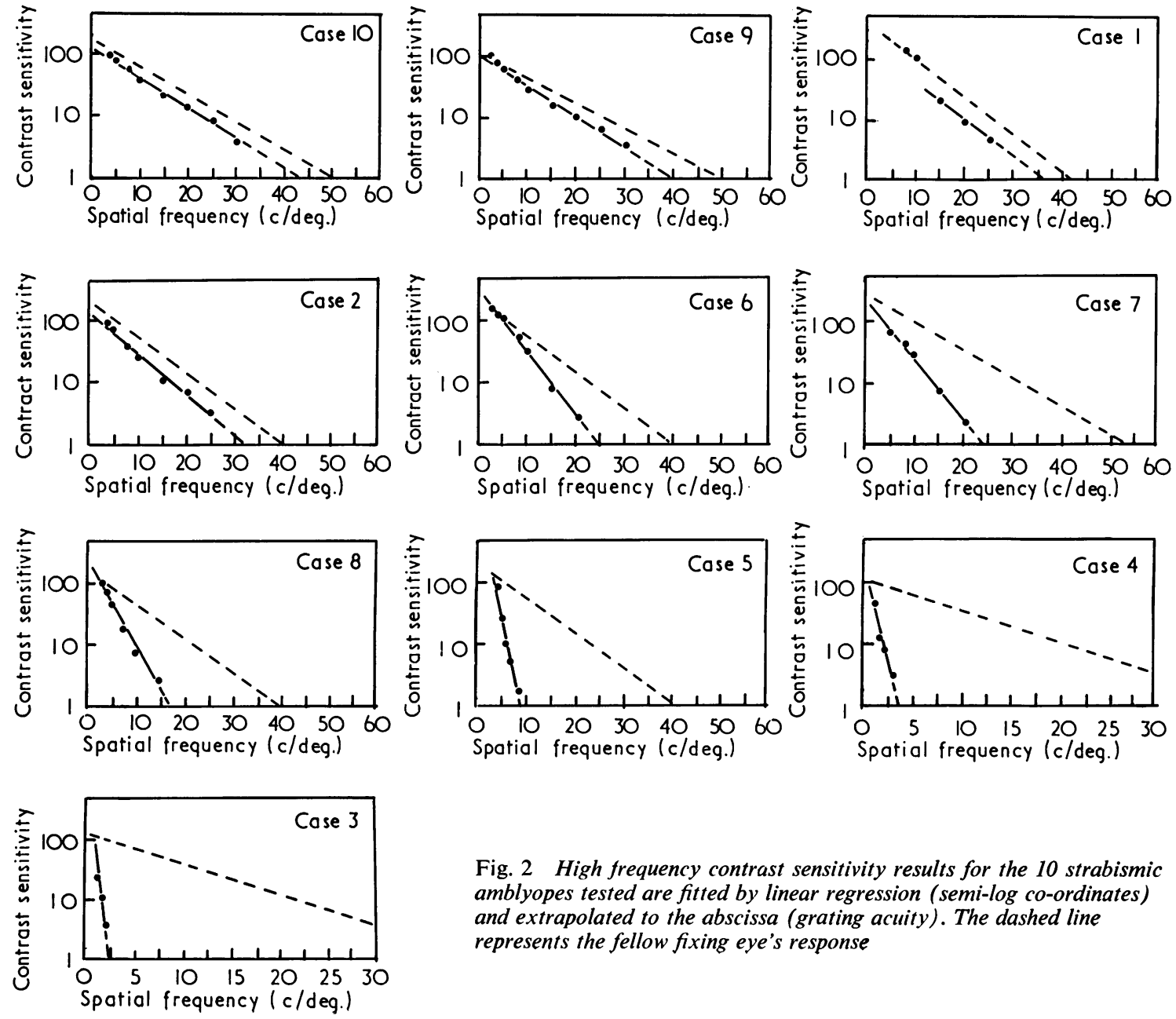

Fig. 2 High frequency contrast sensitivity results for the 10 strabismic amblyopes tested are fitted by linear regression (semi-log co-ordinates) and extrapolated to the abscissa (grating acuity). The dashed line represents the fellow fixing eye's response 
psychometric technique) versus eccentric fixation and the Landolt C, 50\% thresholds of the 10 strabismic amblyopes in the present investigation. No luminance correction is necessary for these normal results, as the luminance difference is slight and is on the plateau, where letter acuity is relatively independent of luminance (Schlear, 1937). These results indicate that, although the correlation coefficient between Landolt $\mathrm{C}$ acuity and eccentric fixation was $0.62(0.05>\mathrm{P}>0.01)$ for the amblyopic eyes, only 3 of the 10 amblyopes (Cases 6, 7, 8 ) showed acuities which were consistent with that expected from the eccentric retinal region used for fixation.

The individual high frequency contrast sensitivity results (SE of mean is equivalent to symbol size) for the 10 strabismic amblyopes from which the grating acuity results were derived (extrapolation to abscissa) are displayed in Fig. 2. In all cases these contrast sensitivity results have been fitted by linear regression; the correlation coefficient was not less than 0.969 , and this corresponded to a significance level less than $0 \cdot 01$. Fig. 3 incorporates these derived amblyopic grating acuities versus eccentric fixation, and this is compared with the normal grating acuity expected of the peripheral retina. The normal grating acuity of the peripheral retina was measured using the same equipment, experimental technique, and conditions for subject ERH. These normal results (displayed in the inset of Fig. 3) are for a $\frac{1}{2}^{\circ}$ field size for frequencies greater than $5 \mathrm{c} / \mathrm{deg}$ and $1^{\circ}$ field-size for $5 \mathrm{c} / \mathrm{deg}$. Care was taken to ensure minimal interference from the 'edge

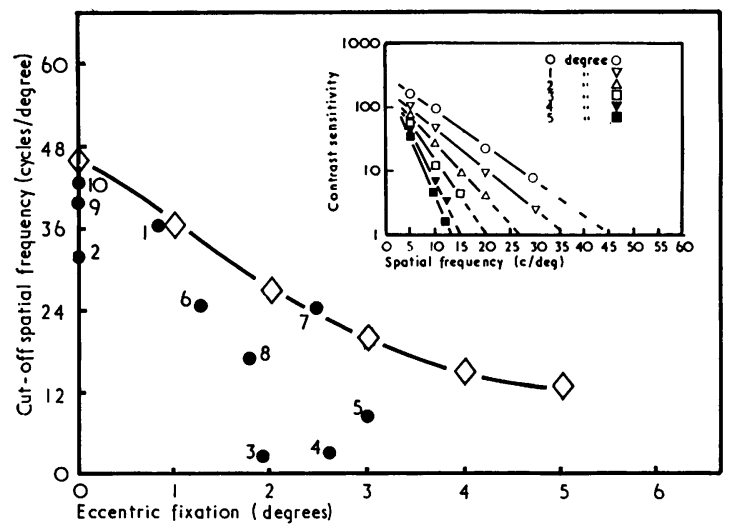

Fig. 3 The relationship between grating acuity for centrically and eccentrically fixating amblyopes (filled symbols) and the normal grating acuity of the peripheral retina (open symbols). The normal grating acuity versus eccentric viewing was derived from the extrapolation of the data in the figure inset. Case numbers shown against dots effect', which can invalidate high frequency measurements for a small field size (Campbell et al., 1969). The results indicate that although the correlation co-efficient was $0.85 \quad(0.01>\mathrm{P}>0.001)$ between grating acuity and eccentric fixation for the amblyopic eyes, only 2 out of 10 amblyopes (Cases 1,7 ) had grating acuities which can be explained solely on the basis of the expected acuity of the eccentric region of fixation.

\section{Discussion}

The results from both acuity tests indicate that 2 populations of strabismic amblyopes can be differentiated when their acuity (letter or grating acuity) is compared with that expected from the eccentric region used for fixation. Acuity for one group of amblyopes can be totally explained by the normally low acuity expected from the peripheral retinal region used for fixation. For a second group of amblyopes there is a further pathological reduction in acuity beyond that expected of the eccentric fixation region. The spatial frequency extent of this depression is yet to be determined. These results explain why the previous two studies (Flom and Weymouth, 1961; Alpern et al., 1967) have produced contradictory results.

It is interesting that there was not absolute agreement between the two acuity tests as to which amblyopes have acuity expected from the eccentric region used for fixation. For example, only Case 7 gave a consistent result for the 2 acuity tests. This may indicate that more than high frequency discrimination is important for Landolt $\mathbf{C}$ detection and that, at least for threshold tasks, an overall frequency depression may be less visually debilitating for detection of complex targets than a differential frequency depression (Bodis-Woolner, 1972).

The conclusion that some amblyopes' visual function is predictable on the basis of the normally low acuity of the eccentric area of fixation is supported not only for grating acuity but also for contrast sensitivity measurements at spatial frequencies within the resolution limit. This finding is clearly seen in Figs. 4 and 5, in which the contrast sensitivity results for Cases 1 and 7 are compared with the sensitivity expected of the normal peripheral retina (ERH results from Fig. 2 inset). Case 1, who has 52' eccentric fixation, shows high frequency $(>10 \mathrm{c} / \mathrm{deg})$ contrast sensitivity, which matches that expected from $1^{\circ}$ eccentric viewing (Fig. 4). Case 7, who has $2.5^{\circ}$ eccentric fixation, shows high and medium frequency contrast sensitivity, which falls within that expected from between 2 and $3^{\circ}$ eccentric viewing (Fig. 5). These results do not support a primary motor bașis of amblyopia, because it has previously 


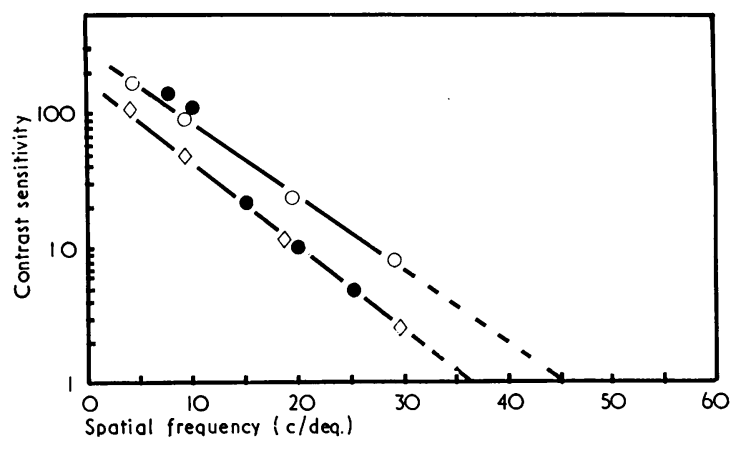

Fig. 4 The high frequency contrast sensitivity results for case 1 (filled symbols) are compared with the sensitivity expected on the basis of the eccentric fixation present (unfilled symbols)

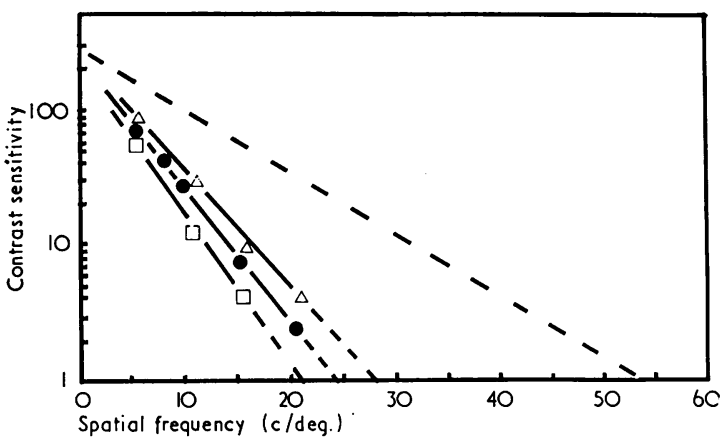

Fig. 5 The high frequency contrast sensitivity results for case 7 (filled symbols) are compared with the sensitivity expected on the basis of the eccentric fixation present (unfilled symbols)

been shown (Hess, in press) that for these two amblyopes the foveal high frequency response is not superior to that of the eccentric fixation region.

The findings of this present investigation may be of interest to clinicians who are concerned with the treatment of amblyopia. Improvement of visual function for some amblyopes will necessitate a reduction in the degree of eccentric fixation, whereas for other amblyopes visual improvement may not necessarily require a change in the fixation behaviour. If the small sample of amblyopes used in the present investigation is representative, this latter response may be more common.
I thank Mr E. R. Howell for acting as a subject for these experiments and for the use of equipment. I would also like to acknowledge the generosity of all my amblyopic subjects.

\section{References}

Alpern, M., Petrauskas, R. R., Sandall, G. S., and Vorenkamp, R. J. (1967). Recent experiments on the physiology of strabismic amblyopia. American Orthoptics Journal, 17, 62-72.

Bodis-Woolner, I. (1972). Visual acuity and contrast sensitivity in patients with cerebral lesions. Science, 178, 769771.

Campbell, F. W., and Gregory, A. H. (1960). Effect of size of pupil on visual acuity. Nature, 187, 1121-1123.

Campbell, F. W., Kulikowski, J. J., and Levinson, J. (1966). The effect of orientation on the visual resolution of gratings. Journal of Physiology, 187, 427-436.

Campbell, F. W., Carpenter, R. H. S., and Levinson, J. Z. (1969). Visibility of aperiodic patterns compared with that of sinusoidal gratings. Journal of Physiology, 204, 283-298.

Finney, D. J. (1947). Probit Analysis. Cambridge University Press: London.

Flom, M. C., and Weymouth, F. W. (1961). Centricity of Maxwell's spot in strabismus and amblyopia. Archives of Ophthalmology, 66, 260-268.

Hess, R. F., and Howell, E. R. (in press). The threshold contrast sensitivity function in strabismic amblyopia; evidence of two-type classification. Vision Research.

Hess, R. F. (in press). Assessment of stimulus field-size factors in strabismic amblyopia. American Journal of Optometry and Physiological Optics.

Lawwill, T. (1966). The fixation pattern of the light adapted and dark adapted amblyopic eye. American Journal of Ophthalmology, 61, 1416-1419.

Millodot, M. (1966). Foveal and extra foveal acuity with and without stabilised retinal images. British Journal of Physiological Optics, 23, 75-106.

Schlear, S. (1937). The relationship between visual acuity and illumination. Journal of General Physiology, 21, 165-172.

Van Buren, J. M. (1963). The Retinal Ganglion Cell Layer. Charles C Thomas: Springfield, Illinois.

Von Noorden, G. K., and Burian, H. M. (1958). An electroopthalmographic study of the behaviour of the fixation of amblyopic eyes in light and dark adapted states, a preliminary report. American Journal of Ophthalmology, 46, 68-72.

Von Noorden, G. K. (1970a). Etiology and pathogenesis of fixation anomalies in strabismus. I. The relationship between eccentric fixation and anomalous retinal correspondence. American Journal of Ophthalmology, 69, 210222.

Von Noorden, G. K. (1970b). Etiology and pathogenesis of fixation, anomalies in strabismus. II. Paradoxic fixation, occlusion amblyopia and microstrabismus. American Journal of Ophthalmology, 69, 223-227.

Wyszecki, G. (1963). Proposal for a new colour difference formula. Journal of the Optical Society of America, 53, 1318-1319. 